\title{
Algumas reflexões sobre a inserção das novas tecnologias nas práticas docentes
}

\author{
Adelma Lúcia de Oliviera Silva Araújo \\ (UFMG)
}

\author{
Rivânia Maria Trotta Sant'Ana \\ (UFOP/UFMG)
}

\begin{abstract}
Resumo
Com este artigo, temos como objetivo discutir a atitude dos sujeitos docentes frente aos desafios de aprender a ensinar e de aprender a aprender como utilizar as tecnologias de informação e comunicação (TIC's) dentro de sala de aula. Apontaremos alguns fatores que são agentes propulsores e/ou inibidores da inserção das mídias na prática docente, dentre os quais, a necessidade da oferta de cursos de introdução à informática. Ao final, adicionaremos sugestões, frutos da experiência docente com professores da rede municipal de ensino mineira, com o objetivo de contribuir para uma discussão sobre a formação dos professores na atualidade.
\end{abstract}

Palavras-chave: Formação de professores, ensino, aprendizagem, novas tecnologias.

\begin{abstract}
This article discusses the attitude of teachers facing the challenges of learning to teach and learning to learn how to use the new information and communication technologies in schools. Several factors are pointed out that can either encourage or else inhibit the integration of media in teaching practices, including the need to offer introductory courses in computer science. Finally, from teaching experiences at state schools in Minas Gerais, suggestions are offered that might contribute to a rethinking of current teacher development policies.
\end{abstract}

Keywords: Teacher training, new technologies, learning, teaching.

\section{INTRODUÇÃO}

Os seres humanos, ao longo de sua história, fizeram uso de vários instrumentos para a preservação de sua sobrevivência. Muito embora não conheçamos registros escritos sobre grande parte dos aparatos usados desde o início de nossa civilização, historiadores têm-nos mostrado algumas evidências da presença humana através de objetos datados de milhares de anos. Segundo consta, seriam os povos malaios os primeiros desbravadores de novos territórios que, ao fazerem uso dos conhecimentos 
sobre correntes oceânicas, ventos, velejamento e movimento das estrelas, conseguiram se espalhar pela Malásia, atravessar o Oceano Índico e o Oceano Pacífico e atingir muitas terras dos diversos continentes. Para tanto, eles utilizaram muitos intrumentos de orientação rudimentares, feitos de cordas, varas e conchas para amarração.

Sempre em busca de condições mais adequadas de sobrevivência e, à medida que o tempo transcorria, e a civilização se desenvolvia, também em busca de riquezas e poder, o homem foi acumulando conhecimento, criando e aprimorando instrumentos, métodos e técnicas. Ao conjunto desses elementos, ou ao estudo deles, denominamos tecnologia; e não se pode pensar na preservação e no desenvolvimento da civilização sem considerar algum aspecto das conquistas tecnológicas. Não é novidade que nossas maneiras de viver, nossas visões do mundo, nossas formas de comunicação e interação, nossa função nas comunidades em que estamos inseridos e certos arranjos e rearranjos de inserção e exclusão social estão relacionados direta ou indiretamente ao conhecimento e utilização de tecnologias empregadas nos mais diversos domínios da atividade humana.

Entre as mais importantes conquistas do homem estão as tecnologias relativas ao armazenamento de informações e à comunicação, dentre as quais, os dois grandes marcos são a escrita - nos diversos suportes em que se tem apresentado ao longo dos séculos - e as chamadas "tecnologias da informação e comunicação" (TICs), fundamentais para a constituição, armazenamento, propagação e transformação do conhecimento, rompendo as barreiras do tempo e do espaço e transformando as possibilidades de interação dos seres humanos.

No que diz respeito à escrita, a partir do advento da imprensa em 1048, invenção atribuída a Gutemberg, o aparecimento do livro revela-se como um marco histórico nos processos de armazenamento e de circulação do conhecimento. A propagação das informações por meio dos livros teve um papel de destaque ao longo dos séculos, não apenas por estar diretamente relacionada ao aumento das possibilidades de acesso ao conhecimento, mas também pela necessidade imperiosa de se aprender a ler e a escrever, habilidades exigidas como passaporte, dentro da hierarquização de classe, para a inserção numa vida social considerada mais elevada. Da Idade Média à Renascença tivemos uma época marcada pela mudança das novas formas do saber, do fazer e, sobretudo, do ser científico. Dentro dessa perspectiva, o acesso à informação se caracterizava como a chave poderosa da inclusão dos que detinham as habilidades de leitura e escrita; em contrapartida, excluídos eram aqueles 
possuidores apenas do conhecimento popular, denominados incultos. Essa distinção entre os incluídos e os excluídos a partir da perspectiva do domínio do código escrito pode ser percebida, ainda nos dias dia hoje, especialmente em países subdesenvolvidos ou em desenvolvimento, onde os índices de analfabetismo costumam ser altos. Esse quadro traz consequências nefastas para a contemporaneidade, na qual estamos vivendo, em ritmo muito acelerado, a grande revolução das TICs. Se nem todos os instrumentos e objetos desse novo arsenal tecnológico dependem do conhecimento do código escrito para serem operados, "para ter acesso ao que oferece o mundo virtual é necessário saber ler e escrever", como nos lembra Aníbal Bragança (2005: 495). Estamos, portanto, vivendo num mundo que, de forma rápida e irreversível, se transforma tecnologicamente, é ainda altamente marcado pela cultura escrita e que exige de nós, cada vez mais, por um lado, conhecimento especializado e, por outro, muita informação geral, além de capacidade crítica, para construirmos uma visão mais global de um mundo midiatizado. Nesse contexto, o sucesso ou o fracasso da nossa inserção, permanência e atuação no mercado de trabalho depende em grande parte, além da escrita, do nosso letramento digital. Se no passado fazia toda a diferença saber ler e escrever, atualmente o mundo exige muito mais de nós: precisamos também saber "navegar".

Com este artigo, propomo-nos pensar o papel do professor que, diante desse quadro, precisa se reposicionar, repensar sua função social e suas práticas de aprender e ensinar; além disso, ao longo do artigo, levantamos algumas das dificuldades que devem ser superadas para o uso efetivo e significativo das mídias na sala de aula.

\section{DISCUSSÃO}

\section{Qual é a principal mudança no papel social do professor e na sua prática pedagógica diante das inovações tecnológicas?}

A primeira grande mudança no papel do professor diz respeito à reflexão sobre sua prática pedagógica. É impossível, nos dias de hoje, um educador atuar de forma eficaz fazendo uso apenas dos velhos métodos, das aulas tradicionais, alheio às mudanças tecnológicas para fins educacionais que se multiplicam ao seu redor. Isso porque os professores atualmente têm diante de si, em sala de aula ou fora dela, uma geração de crianças e adolescentes que não apenas dominam e utilizam as mais variadas 
tecnologias, como também exploram com familiaridade a net e se vangloriam de suas experiências positivas com ela.

Embora essa tecnologia já seja parte do cotidiano de professores e alunos, quer seja fora ou dentro do espaço escolar, Frade (2005) afirma que muitos educadores podem ser considerados analfabetos digitais, pois, apesar de estarem engajados em práticas sociais de uso de instrumentos como o relógio digital, o microondas, o caixa eletrônico dos bancos, ainda têm alguma dificuldade com o computador e a internet ou, quando já estão familiarizados com estes recursos, compreendendo diversas de suas funções e possibilidades de utilização, não estão ainda seguros para empregar as mídias em sua prática docente. Percebe-se, portanto, em alguns ambientes escolares, a discrepância entre alunos e professores no que diz respeito ao conhecimento e ao domínio de habilidades para utilização das novas tecnologias. Se num passado recente, e ainda hoje em regiões menos desenvolvidas, os professores se distinguiam/distinguem dos alunos porque dominavam/dominam o código escrito, enquanto estes últimos não, hoje muitas vezes acontece o contrário no que diz respeito ao domínio das TICs: é frequente encontrarmos alunos com muito mais conhecimento e prática nessa área do que grande parte dos professores. Além da falta de conhecimento e de habilidades para utilização dos novos instrumentos tecnológicos, encontramos muita resistência por parte de certos pais e professores, que demonizam o computador.

Muitos professores resistem à inserção das novas tecnologias em sala de aula por acreditarem que o uso crescente da mídia fará o ensino tecnicista e superficial, outros partem da crença de que haverá substituição do professor pela tecnologia, assim como aconteceu nas indústrias, com a substituição dos trabalhadores por robôs. Estas crenças devem ser confrontadas. Não acreditamos ser verdadeira nem uma nem outra hipótese. Os novos recursos tecnológicos devem ser instrumentos auxiliares de ensinoaprendizagem, contemplando os diferentes tipos de inteligência. Na verdade, o que se defende neste trabalho não é uma utilização irrefletida e desenfreada da mídia no cotidiano escolar, mas a apropriação desses recursos para a criação colaborativa e o desenvolvimento compartilhado de projetos pedagógicos com o propósito de levantar discussão a respeito das mais diversas áreas do conhecimento, levando-se sempre em consideração os saberes já trazidos pelos sujeitos aprendizes. As tecnologias de informação e comunicação devem ser exploradas, conhecidas, manipuladas e usadas com a finalidade pedagógica de aguçar a curiosidade e aprimorar a criticidade dos alunos, fazê-los conhecer suas limitações, ensiná-los a voar, a explorar suas 
possibilidades, ao mesmo tempo em que se deve refletir com eles sobre o poder de convencimento e a força política que cada um desses meios pode veicular; é preciso prepará-los para perceberem o que há de parcialidade nas informações veiculadas.

Não queremos, portanto, fazer uma apologia à utilização dos novos instrumentos e técnicas sem críticas e sem critério, mas sabemos que a demonização das novas tecnologias não cabe mais. Na década de 90 do século XX, quando a internet começou a figurar no quadro das telecomunicações, as preocupações dos estudiosos, e também dos leigos, girava em torno do perigo da "desumanização" do homem, uma vez que se estava inaugurando "um novo tipo de comunicação que tende a privilegiar o diálogo sujeito-máquina e pode chegar a substituir a comunicação humana", conforme palavras de Frederico Mayor, em crônica publicada na revista Correio da Unesco, de fevereiro de 1997. Nesse mesmo texto, porém, o autor dizia ser importante acompanhar as mudanças e até nos adiantarmos a elas, definindo linhas de ação e direções nas políticas educacionais que levassem em conta a utilização das TICs, de forma a contar com os benefícios das mesmas para a ampliação e a melhoria do ensino superior; ainda não se pensava na inserção das TICs no ensino fundamental e no médio. Mais, dizia ser importante, para que a polarização entre os "iniciados e os excluídos" não aumentasse no quadro mundial, que os países desenvolvidos ajudassem “os países pobres a adquirir novas tecnologias, equipar-se, formar pessoal, integrar-se nas redes já existentes”, mas tomando o devido cuidado para não interferir na definição que cada país deveria fazer de suas próprias necessidades, para não gerar uma nova distorção neocolonialista.

Hoje, quatorze anos depois dessas reflexões de Frederico Mayor e de já haver muitos estudos e muita publicação sobre o tema, ainda não podemos dizer com clareza até onde nos levará essa revolução tecnológica, nem podemos prever todos os efeitos dela sobre a nossa "humanidade", mas já temos alguma ideia acerca dos seus riscos e benefícios e de como ela tem afetado as nossas práticas sociais. Sabemos também que tanto a demonização quanto a mitificação das TICs prestam-se mais à manutenção da ignorância e ao aumento do fosso entre incluídos e excluídos. Entendimento que se revela no texto "O Marco de Ação de Dakar", documento redigido e adotado pelos membros da Cúpula Mundial de Educação, em Dakar, Senegal, em abril de 2000. Nesse documento, os países membros da Cúpula se comprometem a atingir uma série de objetivos relativos à meta de Educação para Todos (EPT) até 2015. Dentre os objetivos constantes do documento estão: "melhorar o status, a auto-estima e o profissionalismo dos professores"; "angariar novas tecnologias de informação e comunicação para apoiar 
o esforço em alcançar as metas da EPT”. Desde 2000, está bastante claro nas discussões mundiais acerca da melhoria da educação que, para este fim, não podemos prescindir das novas tecnologias.

Como consequência dessa visão, em texto de 2008, a UNESCO lança o projeto "Padrões de Competência em TICs para professores", com uma descrição detalhada das habilidades específicas a serem adquiridas pelos professores, para que eles possam usar a tecnologia de forma efetiva e criar condições para que os alunos venham a ser:

usuários qualificados das tecnologias da informação, pessoas que buscam, analisam e avaliam a informação; solucionadores de problemas e tomadores de decisões; usuários criativos e efetivos de ferramentas de produtividade; comunicadores, colaboradores, editores e produtores; cidadãos informados, responsáveis e que oferecem contribuições. (HTTP://www.unesco.org/en/competency-standardsteachers)

Ainda nesse texto, há a afirmação de que "As práticas educacionais tradicionais já não oferecem aos futuros professores todas as habilidades necessárias para capacitar os alunos a sobreviverem no atual mercado de trabalho". Esses Padrões de Competência seriam uma espécie de parâmetros para a formação tecnológica a ser implementada em cursos de formação de professores.

Há, portanto, um entendimento da Cúpula Mundial de Educação e da UNESCO de que as novas tecnologias podem e devem ser utilizadas em prol de uma educação de qualidade nos diversos níveis da educação formal, da ampliação do acesso ao ensino, do intercâmbio das informações e das ideias, da interação de estudantes e pesquisadores de diversos países. As políticas educacionais para o séc. XXI em vários países partem dessa crença, e também da crença de que para viver nessa sociedade caracterizada pela informação e baseada no conhecimento, precisamos ser usuários efetivos, reflexivos, seletivos e criativos das novas tecnologias, conforme consta no documento referido.

Nunan (1999:71) afirma que a utilização das novas tecnologias como instrumentos pedagógicos auxiliares facilita uma "aprendizagem independente e colaborativa e está em harmonia com a visão construtivista do conhecimento" própria das "abordagens de aprendizagem centradas no aluno". Percebe-se, portanto, uma mudança de paradigma em processo, não apenas no fazer do professor, mas nas próprias estruturas das salas de aula. Aqueles antigos espaços escolares onde os principais instrumentos auxiliares do ensino eram carteiras, quadro e giz, já não são adequados às demandas atuais; cada vez mais necessitamos da instalação de laboratórios nas escolas, com uma parafernália de mídias eletrônicas que muitos professores desconhecem, não 
sabem como utilizar, ou utilizam sem critério em sua prática docente. O quadro e o giz, ou a caneta, antes instrumentos indispensáveis a uma aula expositiva, caracterizada pela transmissão de conhecimento do professor para o aluno, passaram a ser os mais simples acessórios nas aulas em que o conhecimento é construído colaborativamente entre professor e alunos, também na sala de aula presencial, a exemplo do que já era claramente percebido no ensino à distância. Desta forma, podemos concordar com a afirmação de Tavares (2000):

parece haver uma retro-transição, ou seja, uma espécie de transição de volta, do contexto online para o presencial, em que as experiências que o professor vivenciou em um ambiente online passem a exercer um impacto sobre a prática pedagógica tradicional no ambiente presencial, tornando-a menos centrada no professor.

Mesmo aqueles que nunca tenham atuado como professores na modalidade virtual, ao saberem de relatos de experiências compartilhadas, passam a repensar sua prática e modificar sua atuação na sala de aula presencial, assumindo uma postura menos centralizadora e atuando como aquele que organiza e cria condições para que os alunos atuem, criem, interajam entre si, com o professor e com o mundo sem intermediação, ou intermediados pela máquina.

Diminui com isso a importância do professor? Acreditamos que não. Na nossa percepção, a função do professor está em reformulação, para que ele assuma como o seu principal papel o de orientador e mediador do processo de construção do conhecimento, no qual todos devem estar engajados. Para tanto, é imprescindível que o professor desperte nos alunos uma postura reflexiva sobre o que viram, leram, ouviram, realizaram e manipularam, de forma a fazer sentido com todos os dados e informações trabalhados. O professor perde no que diz respeito à centralização do foco na sua própria figura, mas, no nosso entender, a sua função deve ganhar importância, uma vez que se torna mais complexa. Ele passa a ser o maestro, cuja atuação é fundamental para a harmonia de todos os músicos e os diversos instrumentos na execução da peça musical.

Segundo Ribeiro (2005, passim):

\footnotetext{
"todo processo de educação deve fazer sentido para educador e educandos, permitindo que eles possam transcender a fragmentação do conhecimento para alcançar uma visão inter e trans-disciplinar"; "um projeto de educação tecnológica deve ter como foco a interdisciplinaridade, a formação integral do homem, a mediação entre ciência e tecnologia, cultura e conhecimento e entre homem e sociedade."; "um projeto de educação tecnológica precisa ter intencionalidade e respaldo teórico"; "a educação, inclusive a tecnológica, deve estimular o raciocínio humano, sobretudo, cabe à educação resgatar o homem da sua pequenez, ampliando
} 
os horizontes, buscando outras opções, tornando as pessoas mais sensíveis e comunicativas."

Assim, não basta inserir novos instrumentos na sala de aula. É preciso saber que instrumentos utilizar e como fazê-lo para fins educacionais, conhecendo, antes, profundamente, o que ensinar e como aprende quem está aprendendo. É preciso também que o professor esteja disposto a aprender e a refletir constantemente sobre sua prática docente. Um professor da educação presencial que queira se aventurar a trabalhar com os novos recursos em sala de aula deve saber que o uso da tecnologia tem que ser planejado com a visão de servir ao objetivo pedagógico. Inicialmente, deve saber a diferença entre o que é aprender e o que é ensinar, para logo após decidir como conceber um projeto pedagógico centrado no ensino-aprendizagem que contemple a inserção desses novos recursos. Faz-se necessário ter um conhecimento mínimo de manipulação das novas TICs para poder decidir o porquê, para quem, quando, onde e como usá-las para atender aos seus objetivos. Ademais, precisa estar atento às mudanças do mundo, interessar-se por aprender, participar, descobrir como trabalhar na construção do saber.

Se considerarmos as afirmações de Ribeiro verdadeiras, e nós consideramos, percebemos que, especialmente nos dias de hoje, diante de todo o arsenal tecnológico e do grande volume de informações com que devemos lidar, além da postura descentralizadora que se exige do professor diante desse quadro, podemos dizer, sem medo de errar, que a educação de qualidade para todos, como deseja a Cúpula Mundial de Educação, a UNESCO, os que atuam na área de educação e, por fim, toda a sociedade empenhada na promoção do ser humano, só pode ser alcançada com a valorização dos professores e de sua função. Essa valorização passa não só pelas conhecidas questões relativas a melhores condições de trabalho e a melhoria salarial, como também pela formação, que deve, de fato, preparar o professor para a complexa tarefa que se exige dele. No que diz respeito ao letramento digital do professor e à discussão sobre a utilização da mídia na sala de aula, os cursos de licenciatura, no geral, falham. A maior parte não inclui em seus currículos disciplinas ou atividades que enfoquem o tema. A formação que os educadores recebem nas instituições de ensino não está compatível com os conhecimentos e habilidades requeridos pelo trabalho com jovens altamente engajados no mundo midiático. Esses educadores não sabem como realizar mudanças tão profundas na sua prática docente. Por terem essa lacuna em sua 
formação, confundem desconhecimento com aversão e resistem a aprender a utilizar e a experimentar as tecnologias em suas aulas, mesmo que de forma incipiente.

\section{Como seria a prática pedagógica desejável de um professor nos dias de hoje?}

Hoje é visível a necessidade de uma educação mais dialógica na qual o professor assuma mais o papel de moderador ou facilitador das interações em sala ao invés daquele papel de especialista que despeja conhecimento no aluno. Mesmo sendo o coordenador, mediador e aquele que explica o assunto e traz de volta ao foco da discussão o tópico em estudo, não deve ser o professor o único a falar, a explicar, a questionar, abrindo espaço para a participação e contribuição dos alunos, tornando-se estes, portanto, co-partícipes da construção do próprio conhecimento. Para que o trabalho dê certo, no entanto, é preciso que essa postura transcenda a sala de aula e chegue aos coordenadores, diretores, enfim, a toda a equipe pedagógica e administrativa da escola, consolidando uma visão do que seja uma prática educativa desejável, conforme defende Berge (1997).

Collins e Berge (1996) citam alguns elementos significativos na mudança da prática pedagógica dos professores quando estes saem da experiência presencial para a docência virtual. Discutiremos apenas alguns destes tópicos por acreditarmos que eles podem estar mais relacionados à mudança de postura/papel do professor em sua prática pedagógica, do que propriamente ao ambiente em que se vai trabalhar. De um lado, encontra-se o educador mais centrado nas aulas tradicionais e que se sente pressionado, a contragosto, a utilizar novas tecnologias no seu cotidiano escolar; de outro, está o professor mais aberto às mudanças. A primeira postura normalmente se caracteriza pelo foco principalmente na preparação do tópico e na exposição do conteúdo por parte do professor. Deixando claro que consideramos importantes as etapas de preparação e de exposição do tema, ressaltamos que a segunda postura é mais enriquecedora, uma vez que permite uma transformação do papel do educador: o antes sujeito centralizador dá lugar ao orientador e provedor de recursos, para que, num ambiente que estimula a curiosidade, a participação e o desenvolvimento da autonomia dos alunos, estes se tornem questionadores, críticos e comprometidos com o seu próprio conhecimento, e também com o do grupo, já que todos, professor e alunos, trabalham em conjunto para construir conhecimento. São muitas as exigências do mundo atual e, com certeza, uma delas é saber trabalhar colaborativamente; aquele que permanece solitário tem menos 
chance de sobreviver, inclusive profissionalmente, daí a grande importância que se dá às redes de relacionamento hoje em dia, pessoais e profissionais.

Dentro desse quadro, se inserem as TICs, ampliando as possibilidades de comunicação. O educador, ao introduzir um tópico, gera debate e questionamentos, promove a reflexão, cabendo aos alunos o aprofundamento do estudo sobre o tema em questão e a execução de tarefas propostas, tentando, de forma colaborativa, encontrar soluções para problemas que se colocam em discussão. Com a participação ativa dos aprendizes nas atividades, são exploradas as múltiplas visões do grupo, e ricas experiências são trazidas por todos ao centro das discussões, construindo-se desta forma uma educação para aceitação da diversidade de opiniões, de posturas e, consequentemente, abrindo espaço para o surgimento de novos temas a serem discutidos em outros encontros. O ganho mais visível na prática pedagógica do educador acessível à mídia é que ele deixa de ser solitário e passa a ser um membro efetivo da equipe de aprendizagem. Essa mudança geralmente vem acompanhada de uma flexibilização também nas formas de avaliar, levando-se em conta a participação dos alunos. O resultado dessa transformação pode ser percebido qualitativamente pela resposta afirmativa destes, na ânsia de aprender mais e de forma mais integral, prazerosa, pois, ao se sentirem parte dessa prática e por estarem engajados nela, os alunos se sentem responsáveis pela construção do seu conhecimento no espaço escolar, passando, aprendizes e professores, a serem agentes no ambiente de compartilhamento de experiência e saberes. Esse fato é destacado por Oliveira e Carvalho, quando dizem que "há mudança na postura dos alunos quando estes deixam de ser simples ouvintes e com isto se minimiza o abismo existente entre esses e os educadores".

Apenas o discurso oral e linear do professor na sala de aula tem-se tornado ineficiente para reter a atenção dos alunos. A escola, enquanto espaço de educação formal, continua bastante fechada a inovações tecnológicas e não se incomoda em carregar o peso de ser castradora do saber não formalizado, de ser um espaço desatualizado e o último reduto a incorporar o uso das mídias como instrumento pedagógico. Ao se abrir a escola à utilização de meios diversificados de propagação de conhecimento e à utilização de estratégias de ensino-aprendizagem mais flexíveis e individualizadas, é frequente obter como resultado respostas mais eficientes dos alunos.

Outro motivo que justificaria a inserção das novas tecnologias na sala de aula seria a preparação dos alunos para viverem numa sociedade instável e multifacetada. As tecnologias na sala de aula promoveriam a autonomia do aprendiz, ao exigir deste 
responsabilidade na execução de suas tarefas, possibilitaria o desenvolvimento da sua criatividade na solução dos problemas propostos, além de desenvolver a sua capacidade de recolher, relacionar e escolher informações que respondam a seus questionamentos, colaborando na formação do sujeito educando ativo, não apenas no que diz respeito ao conteúdo programático escolar, mas também à sua formação como ser humano.

A introdução efetiva da mídia na prática escolar diminuiria a distância entre a escola tradicional e a chamada escola paralela, caracterizada pela oferta de uma riqueza indescritível de recursos tecnológicos, que coloca o sujeito aprendiz como ser responsável pelo próprio aprendizado, alcançando resultados surpreendentes, pois, ao motivar a descoberta, a tentativa de erro e acerto leva o indivíduo encontrar as respostas.

O professor, já detentor de importantes habilidades em sala de aula, deve aprender a manipular as tecnologias e fazer a adequação do que já sabe ao uso dessas mídias.Um exemplo de estratégia vitoriosa que gostaríamos de relatar aqui é a da professora Giuvana Wenk dos Santos, da EEB Dom Pio de Freitas, de Joinvile, Santa Catarina. Ela sagrou-se vencedora do $2^{\circ}$ Prêmio Luís Eduardo Magalhães por ter desenvolvido e coordenado o projeto "Modificando a Escola através da Educação Ambiental - Construindo a Agenda 21 Escolar". Em seu depoimento ao Jornal de Educação, a professora afirmou não ter feito o projeto sozinha, mas que contara com a ajuda de uma equipe formada por alunos e professores de sua escola, os quais desenvolverem juntos uma proposta de trabalho colaborativa. Acrescentou ainda que a ideia do projeto surgiu a partir das suas observações do comportamento dos alunos em relação à escola.

Ao relatar esta experiência premiada gostaríamos de enumerar caminhos possíveis de intervenção trilhados pela professora Giuvana e equipe, que não apenas modificaram a prática docente, mas que ressignificaram o fazer educação de toda a comunidade, dentro e fora do espaço escolar: equipe diretiva, equipe pedagógica, alunos e pais. A primeira etapa do projeto foi dedicada à concepção de como construir uma ponte para estreitar os laços entre a escola e a comunidade, já que a professora percebera que "as práticas pedagógicas, a rotina escolar, a falta de participação dos alunos nas decisões da escola, imprimiam um sentimento de não pertencimento a esse espaço, voltando à visão da escola como sendo propriedade do governo e não da comunidade". Na segunda etapa ela selecionou "um tema para o projeto que maximizasse a participação de todos os seus integrantes em diversas atividades, de forma organizada e dinâmica, melhorando a relação da escola com a comunidade e 
abrindo canais de expressão dos alunos". Seguindo os princípios de cooperação e parceria na implementação da agenda 21 , colocou no centro da discussão o tema "a escola que temos e a escola que queremos" e solicitou dos alunos que expressassem suas percepções e desejos por meio de textos, desenhos, poesias, músicas, maquetes, etc.

Como passo seguinte, ela foi em busca do apoio ao seu projeto, conversando com todos os professores e demais profissionais da escola, convidando-os a participarem de uma reunião pedagógica para discussão e diagnóstico da escola. Esse instrumento de pesquisa, quando aplicado, não só "confirmou o que pensavam os professores, mas também retratou a visão dos alunos, reforçando a necessidade de mudança na prática pedagógica, nas formas das relações sociais, assim como da estrutura física da escola", conforme palavras de Giuvana.

A partir desse exemplo real, vê-se que o pontapé inicial dado por uma professora engajou não apenas a escola, mas toda a comunidade e fez com que todos refletissem sobre as relações que se estabelecem diariamente na comunidade, dentro e fora do espaço escolar e, por conseguinte, redefiniram a prática docente e a postura assumida pelos alunos em relação à própria construção do aprendizado. Podemos, portanto, pensar em usar etapas assim em um projeto que envolva a inserção das mídias na escola, proporcionando maior engajamento dos alunos, por estes se sentirem elementos que fazem a ligação entre o saber do mundo exterior e o do ambiente escolar, traduzindo os significados dos saberes da escola para o mundo de fora e vice-versa.

Todos estes tópicos discutidos anteriormente, porém, não terão relevância no cotidiano escolar se todo o corpo diretivo da escola, juntamente com alunos e pais não tocarem a mesma nota no mesmo tom. Não adianta apenas a troca de estratégias de ensino se todos os que fazem a escola não acreditarem e não se sentirem participantes ativos desse trabalho. Planejar uma aula usando tecnologia apenas para se mostrar inserido no universo digital pode ter desdobramentos indesejáveis e resultados desastrosos. O professor precisa, para acessar os dispositivos midiáticos, ir muito além do conhecimento formal, do domínio da escrita e da leitura. Mesmo sendo defensoras do uso das mídias como instrumento poderoso de ensino-aprendizagem reiteramos aqui ser importante não apenas o modo como a tecnologia é utilizada, mas, essencialmente, a clareza acerca do projeto pedagógico que se quer desenvolver e que embasa todas as escolhas a serem feitas em sala. 


\section{CONCLUSÃO}

Como educadores, e especialmente como professores de língua materna, temos a grande responsabilidade de trabalhar pelo domínio da escrita, pela competência na leitura, pela construção significativa do conhecimento e pela sua propagação, pela promoção dos alunos e pelo nosso próprio crescimento profissional. As novas tecnologias, utilizadas com critério, podem contribuir para tudo isso, ou seja, quando utilizadas com adequação e propriedade, potencializam os resultados positivos do processo de construção do conhecimento.

Assim, é preciso diminuir o fosso que, aparentemente intransponível, separa a realidade da escola da realidade extra-escolar. Se por um lado a escola se mostra hermeticamente fechada em relação às mudanças e resistente às recentes inovações tecnológicas, por outro, a comunidade também exige uma postura reguladora e tradicionalista da escola, como se esta fosse um lugar sagrado, desaprovando as inovações representadas pela inserção das tecnologias como instrumento de aprendizado. Parte da resistência é resultado da dificuldade dos professores em relação às mudanças nas próprias práticas pedagógicas, por causa da falta de conhecimento para operacionalização das tecnologias e, por último, de capacitação pedagógica, para preparar, programar, construir, analisar e dar finalidade à inserção das tecnologias no cotidiano de sala de aula. Cabe aos membros da instituição escolar, com o apoio da comunidade de pais, a discussão para encontrar formas de inserção das mídias na sua prática de ensino, dentro do seu projeto pedagógico. Para as discussões, podemos encontrar subsídios em muitas publicações recentes nacionais e internacionais, que trazem, inclusive, sugestões de projetos e atividades a serem desenvolvidos no ambiente escolar.

Outra ação importante para se conseguir a inserção efetiva das TICs nas práticas docentes é a reformulação do currículo das licenciaturas, para a inclusão de disciplinas e/ou atividades curriculares com o objetivo de formação crítica dos novos docentes, para uma prática pedagógica que leve em conta a complexidade do nosso tempo, contemplando a utilização efetiva e significativa dos novos recursos tecnológicos na educação, tanto na modalidade de ensino presencial quanto na modalidade à distância. 


\section{REFERÊNCIAS}

Abreu, M. \& Schapochnik, N. (orgs.). (2005). Cultura letrada no Brasil: objetos e práticas. Campinas: Mercado das Letras, ALB; São Paulo: Fapesp, 518 p.

Bragança, A. O pretérito futuro do livro. (2005). In: Abreu, M.\& N. Schapochnik (orgs.) Cultura letrada no Brasil: objetos e práticas. Campinas: Mercado das Letras, ALB; São Paulo: FAPESP. p. 487-498.

Brandão, C. R. (org) (1980). A questão política da Educação Popular. 2. ed. São Paulo: Brasiliense, p.7-10.

Bonilla, M. H. S. (2004). Linguagem, tecnologia e racionalidades utilizadas em sala de aula; interfaces possíveis. $27^{a}$ Reunião Anual da ANPED, Caxambu. Disponível em http:// www.anped.org.be. Acessado em 26/06/2010.

Cadeira, C. (2002). Do papiro ao papel manufaturado. Revista Espaço Aberto, USP, outubro de 2002, n' 24.

(HTTP://www.usp.br/espacoaberto/arquivo/2002/espaco24out/print/ptvaria.htm)

Collins, M. \& Berge, Z. L. (1996). Facilitating interaction in computer mediated online courses. FSU/AECT Distance Education Conference, June, 1996. Available in http://star.ucc.nau.edu/ mauri/moderate/flcc.html.

(1996). Example case studies in post-secondary, on-line teaching. In: G. Hart \& J. Mason. Proceedings of the 'Virtual University Symposium'. Melbourne, Australia, November 21-22, 1996, pp: 99-105.

Coscarelli, C. V \& Ribeiro. A. E (Orgs) (2005). Letramento digital: aspectos sociais e possibilidades pedagógicas. Belo Horizonte: Ceale, Autêntica.

Moderno, A. (1985). Para uma pedagogia do audiovisual. Revista da Universidade de Aveiro, vol.6.

Moran, J. M. (1995). Novas Tecnologias e o reencantamento do mundo; tecnologia Educacional. São Paulo, vol. 23, n. 126.

. (1997). Como utilizar a internet na educação. Revista Ciência da

Informação, Vol 26, n. 2, maio-agosto, p. 146-153.

. Ensino e aprendizagem inovadores com tecnologias. Artigo disponível online in http://www.eca.usp.br/prof/moran. Acessado em 28/05/2010.

Nunan, D. (1999). A foot in the world of ideas: graduate study through the Internet. Language Learning\& Technology, 3 (1), July, pp.52-74.

Padrões de Competência em TIC para Professores, UNESCO, 2009. (HTTP://www.unesco.org/en/competency-standards-teachers) 
Röring, C \& Backers, L. O professor e a tecnologia digital na sua prática educativa. Artigo disponível online em

http://www.pgie.ufrgs.br/alunos_espie/espie/luciana/public_html/mara.doc. Acessado em 15/06/2010.

Setzer, V. W. Uma revisão de argumentos em favor do uso de computadores na educação elementar. Artigo disponível online in http://www.ime.usp.br/ vwsetzer. Acessado em 16/05/2010.

Tavares, K. (2000). O papel do professor - do contexto presencial para o ambiente online e vice-versa. Conecta, número 3 - nov/dez/.

Lima, J. O et al. A Resistência do professor diante das Novas Tecnologias. Em http://www.meuartigo.brasilescola.com/educacao/a-resistencia-professor-diante-dasnovas-tecnologias.htm. Acessado em 8 de maio de 2010.

Mayor, F. (1997). O ensino superior e as novas tecnologias. O correio da Unesco, Ano $25, \mathrm{n}^{\circ} 2$, fevereiro, pp. 38-39.

Nez, E \& Silva, E. M. Um relato de experiência de inclusão de tecnologias na escola pública do estado de Mato Grosso. Em I ENINED - Encontro Nacional de Informática e Educação. Disponivel em http://www.inf.unioeste.br/enined/anais/enined/A04.pdf

\section{AS AUTORAS}

Adelma Lúcia de Oliveira Silva Araújo é professora orientadora-tutora do Curso de Especialização à Distância - Mídias na Educação, da Pró-Reitoria de Assuntos Especiais da UFOP. Licenciada em Língua Inglesa pela UFOP, com Mestrado em Estudos Linguísticos - Estrutura sonora da Linguagem, pela UFMG, atualmente é doutoranda na Linha Linguagem e Tecnologia do Programa de Pós-Graduação em Estudos Linguísticos da UFMG. Áreas de atuação e pesquisa: Fonética, Fonologia, Letramento de adulto, Formação de professores, Tecnologia de Comunicação e Informação.

E-mail: adelmaa@yahoo.com.br

Rivânia Maria Trotta Sant'Ana é professora do Departamento de Letras da Universidade Federal de Ouro Preto, mestre em Literatura Brasileira pelo Programa de Pós-Graduação em Estudos Literários da UFMG e doutoranda na linha Linguística do Texto e do Discurso do Programa de Pós-Graduação em Estudos Linguísticos da UFMG. Áreas de atuação e pesquisa: Língua Portuguesa, Linguística do Texto e do Discurso, Letramento de Adultos e Formação de Professores.

E-mail: rivaniatrota@hotmail.com 